\title{
The Study of the Reflection of Cost Control on Financial Management
}

\author{
Youming $\mathrm{He}^{*}$
}

Ningbo Polytechnic, Ningbo, China

\begin{abstract}
Cost control is one important topic in today's financial management. It not only reflects the scientific approach of organizations' management, but also shows optimizes the companies' structure. Finance is a critical element of companies' long-term and sustainable development, which has to some extent comprises the cost control in its scope. This thesis tries to elaborate the importance of cost control in financial management and unveil the cost control problems in modern enterprises. The author overlooks the general financial management system in China and probes the weaknesses of it. After a series of the analysis, the author proposes three recommendations: one is to adjust the orientation of cost control, the other two are to provide the necessary political support and to establish an independent department within the company.
\end{abstract}

Keywords: Business control, cost control, financial control, positioning, problem.

\section{INTRODUCTION}

After the transition from central economy to market economy, the level of Chinese financial management keeps increasing. The significance of financial management has received more and more attention from the enterprises' management level. In addition, the numbers of financial decisions have grown constantly. At the same time, the emphasis of financial management is in the planning and operation of capital. The companies have employed effective regulation to their financial operation, to distribute the risks and to prevent the risks, for the purpose to prolong the lifespan of their companies' survival and development.

In the contemporary days, the severe and competitive external environment has forced the companies to make a change, and the modern and advanced financial management theories are introduced to China (An, M.S. and Chen, L, 2000). In this certain context, another concept, cost control, is brought to the nation as well [1]. Cost control is a management term, which relies on the effective distribution of cost and cash flow [2]. But it is not a pure economic term, as it can be expanded across the whole business process of the company. Furthermore, it can impose a significant impact on the strategic decision of the management level. In modern enterprises, cost control is a meaningful topic to be largely associated with the financial management [3]. It has been regarded as one main topic for today's management levels.

This thesis takes the perspectives of the practice of cost control in enterprises' financial management and shows its implementation in modern enterprises. There are four sessions in total. The first session introduces the definition and categories of cost control. The second session clarifies why the cost control is so important to the financial management. The author tries to give the information of its established system and to indicate its importance in this context. And in the further session, the problems of the in accurate positioning

*Address correspondence to this author at the Ningbo Polytechnic, Ningbo, China; E-mail: cyyg015@sina.com and biased concepts are unveiled. In the recommendation part, the author proposes three feasible recommendations to improve the current cost control system in financial management in the modern enterprises.

\section{OVERVIEW OF COST CONTROL}

With the intensity of the market competence, the contents of the cost is expanding to different steps of the enterprises' operation. It does no longer refers to the manufacture cost only. Instead, the cost of an enterprise shall include all the expenditure of a product's lifespan with the manufacture cost included. From this perspective, we may find that the cost today can be translated as an integrated term with manufacture cost, use cost, research and development cost, maintenance cost and etc.

Because the definition of cost is a widened concept today, the contents of cost control is changed accordingly. The definition of modern cost control is inclusive. Specifically, cost control refers to the management-relevant interventions or regulations on the cost control to achieve the predefined cost control target for a short or long course.

There are many types of cost control interventions employed by the enterprises. According to the control stage, there are regular controls and pre-task controls. Then, in terms of the cost approaches, they are absolute control and relative control. While controlling the cost, the enterprises usually follow the principles. Some of the principles are the economic principles, comprehensive principles, the integration of responsibility, right and interests, the localization principles and exceptions. In modern enterprises, the standardized cost system has been established to maintain the daily regular operation as well as the exceptional cases.

\section{THE IMPORTANCE OF COST CONTROL IN FI- NANCIAL MANAGEMENT}

In recent years, the financial crisis has imposed a negative impact on the global economy. Many small and me- 


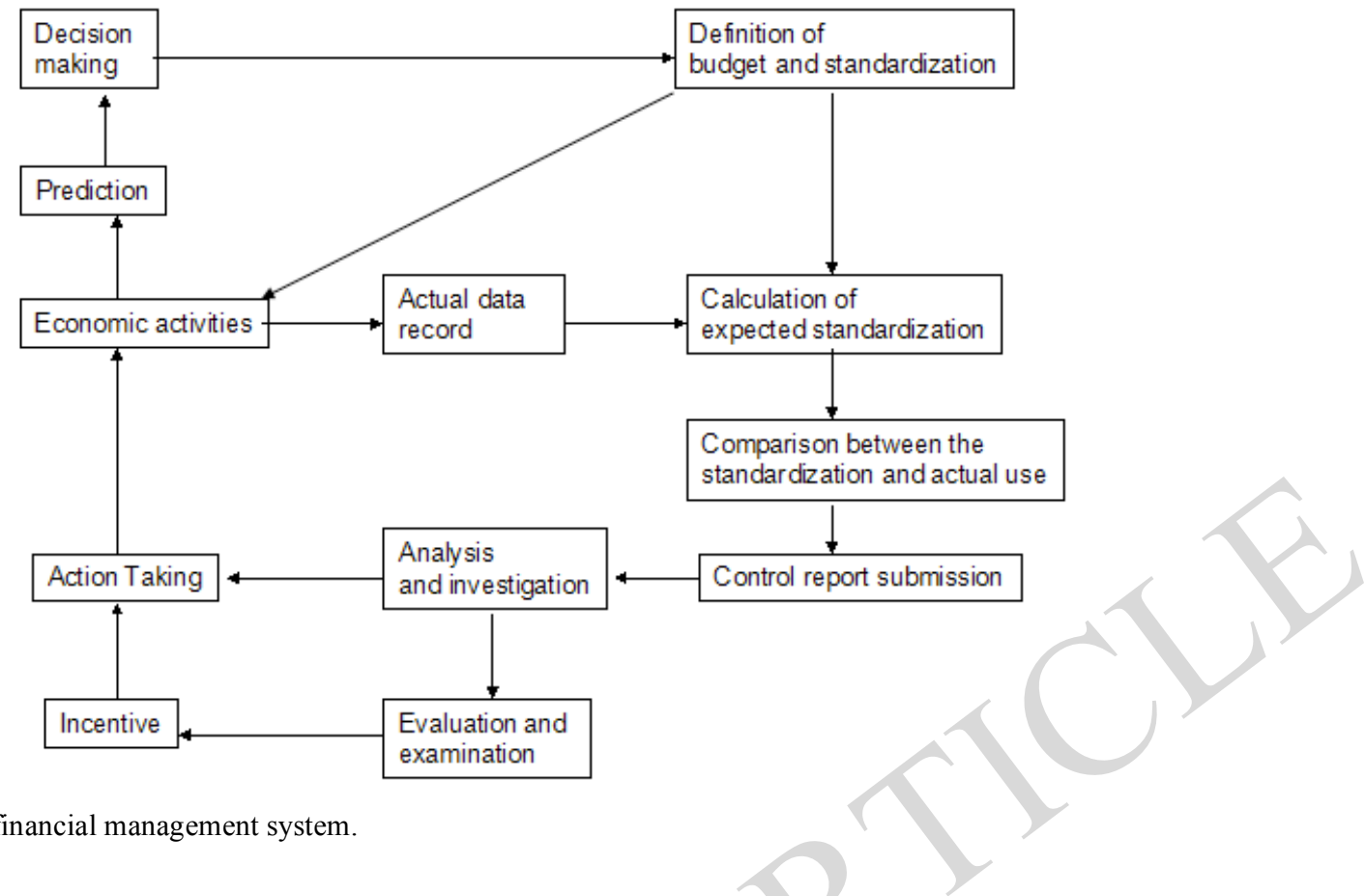

Fig. (1). A standardized financial management system.

dium-sized companies are faced with the decreasing operation abilities in this context [4]. In order to increase the profits, as well as to survive in the market, it is meaningful for them to implement cost control. The functions of cost control in financial control can be found at the below aspects:

\subsection{The Reflection of Financial Status}

The cost control is able to show the budget of the enterprises and their balance situation in a specific course, which is largely associated with the profits of the enterprises and its competitiveness in the market.

Considering the intensive competition in the market, all the financial managers, the direct investors, the debt owners and other stakeholders might be particular about the financial status of the company. The cost control report is one report containing the cash flow and the usage of cash. Its control result directly influences the further decision making, thus, biasing the results of debt cleaning up and the profits distribution.

\subsection{The Functions Throughout the Financial Manage- ment Process}

Basically cost control is one important component in the financial management process. Its management mode is a reflection of the financial management output. In the past, many enterprises only list out the expenditure of financial cost, but they not calculate or examines the management cost. With an excessive reliance on the financial department, the active collaboration is not established within the companies. While in the modern enterprises' system, the requirement to introduce cost control has turned to magnify the financial support, material support and human resources in the process of business management.

Fig. (1) gives the overview of a standardized modern financial management system, from which a comprehensive and constant requirement for cost control and examination of it is indicated.

\section{THE PROBLEMS OF COST CONTROL IN MOD- ERN FINANCIAL MANAGEMENT}

\subsection{Inaccurate Positioning of Cost Control}

Traditional cost accounting only concerns the direct material, processing and non-manufacture cost [5]. On the other hand, the enterprises usually placed the emphasis on the manufacture step, but ignore the other steps including research and development, designing, procurement, selling, update, investment and other regular business operation. And the control approaches are simplified, which hinders the effective cost management.

Moreover, according to the traditional classification of department responsibilities, the finance department only carries out the simple analysis, calculation, but lacks the systematic summary or monitoring, thus, the exact implement of cost control is not following its design to form a systematic structure within the company.

\subsection{Staggered Cost Control Concepts}

The ultimate purpose of enterprises' cost control is to reduce expenditure, decrease the cost, and to maximize the interests of the stakeholders. Traditional cost control takes cost saving as the main criterion, and also leads to another fact that some enterprises seek for the possibilities of reducing the cost but do not combine the real business situation of the companies [6]. Therefore, the approach they choose is to take the advantage of prices to struggle for a larger market share.

In addition, the importance of financial analysis, is not combined with the performance evaluation. The pre-design of the cost control is not being implemented by many of the modern enterprises. In this way, the decision making is not benefited by the effective cost control system. 


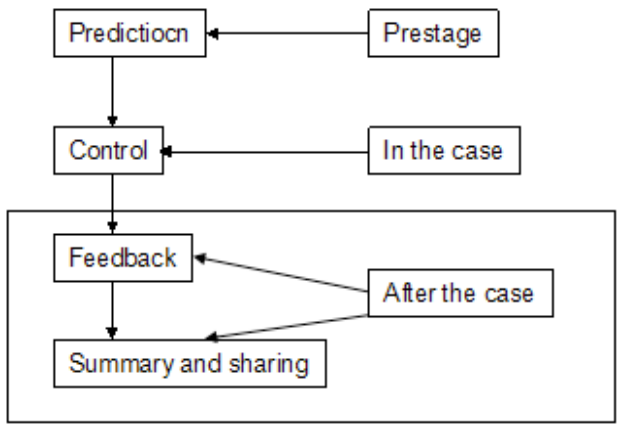

Fig. (2). The functions of independent business control department.

\section{RECOMMENDATIONS FOR COST CONTROL IN MODERN FINANCIAL MANAGEMENT}

\subsection{Adjustment of Cost Control Concepts}

Cost accounting is a systematic project, which is largely associated with different aspects of enterprises. Basically all the employees are supposed to engage in the control process. Modern managers have to enhance their consciousness of self-control and the awareness of their employees. And the concept has to change to the cost-control orientation rather than the cost-examination only, otherwise, the ultimate strategic purpose is not feasible in these companies.

\subsection{Definition of Strategies and Regulations to Support Cost Control Implementation}

It is true that the manufacture of products create cost, however, in the implementation of cost control, the designing, selling and after-sales services all consume the resources. The strategic cost control project is supposed to overlook the industrial market, the enterprises, the competitors' financial status, as well as the non-financial one. The enterprises if cannot include the innovation costs into the cost control system, they will be faced with more adverse operation situation in the future. Hence, the companies are recommended to form a well-established and comprehensive regulations to define the cost control contents as well as its target.

\subsection{Establishment of Internal Business Control Depart- ment}

It is necessary to establish an internal control department, which can relieve the high pressure of the financial department from cost control and more importantly strengthen the control effectiveness in the company $[7,8]$.

With the independent business control department, the incomprehensible issues of the existing financial accounting system can be improved. The random check is a monitoring mechanism to the employees to some extent, and it is a supplementary to the cost control system. It is expected to function in the whole process of modern financial management system, as indicated in Fig. (2).

\section{CONCLUSION}

This paper reviews the definition of cost control and illustrates its changing meanings in today. Along with the expansion of its meaning, the cost control system has been updated as well. This system has been included in the modern enterprise management system. More importantly, inside the companies the association of the enterprise financial management is established with the cost control. It is meaningful to maximize the cost control functions as a provision of the financial status and a requirement for the scientific financial management. However, it is also interesting to find that the current cost control system in China is not perfect, therefore, it is meaningful for the companies to alter the situation by replacing the inaccurate positioning, defining the necessary regulations and establishing an independent control department in the company.

\section{CONFLICT OF INTEREST}

The author confirms that this article content has no conflict of interest.

\section{ACKNOWLEDGEMENTS}

Declared none.

\section{REFERENCES}

[1] M.S. An, and L. Chen, "Modern Management and Accounting," Shanghai: Accounting Press, 2000.

[2] Q.W. Fleming, "Cost or Schedule Control Systems Criteria: The Management Guide to C/SCSC. Illinois: Probus Publishing Co, 1992.

[3] Y.F. Han, "Important Status of Cost Control in Small and MediumSized Enterprises," Huizhi High-Tech Academy, vol. 1, pp. 25-26, 2010

[4] P.J. He, and C. Wang, "Internal Business Control Essence," China Economy Press, 2002.

[5] C.D. Li, "Modern Management Accounting," Shanghai: Shanghai Accounting Press, 1999.

[6] Y. Sun, "Improving the Internal Accounting Control inside the Companies," Finance Circle (Academic), 2010.

[7] X.L. Zhang, "The Importance of Cost Control in the Financial Management of Medium-Sized Enterprises," Huizhi Science Technologies College Paper, 2010.

[8] S.L. Zheng, and S.M. Xu, "A Study on the Existing Problems and Solutions of Internal Accounting Control," Accountant, 2010.

(C) Youming He; Licensee Bentham Open.

This is an open access article licensed under the terms of the (https://creativecommons.org/licenses/by/4.0/legalcode), which permits unrestricted, noncommercial use, distribution and reproduction in any medium, provided the work is properly cited. 